\title{
Fatigue Properties of Cruciform and Flange-gusset Joints Using Normal and High Strength Steels
}

\author{
Balázs József Mecséri1 ${ }^{1 *}$, Balázs Kövesdi \\ ${ }^{1}$ Department of Structural Engineering, Faculty of Civil Engineering, Budapest University of Technology and Economics, H-1111 \\ Budapest, Múegyetem rkp. 3., Hungary \\ *Corresponding author, e-mail: mecseri.balazs@epito.bme.hu
}

Received: 20 April 2019, Accepted: 04 March 2020, Published online: 06 April 2020

\begin{abstract}
The objective of this paper is to investigate and compare the fatigue behavior of Normal Strength Steel (NSS) and High Strength Steel (HSS) welded specimens (cruciform and flange gusset joints). Numerous specimens were tested in the framework of the research project. The experimental S-N curves of the test specimens are determined and analyzed by mathematical statistics to consider the uncertainties and scatter of test results. Statistical analysis of the S-N curves showed that the fatigue behavior of as-welded flange gusset joints is identical in the cases of HSS and NSS specimens, which means that there is no difference in the fatigue lifetime depending on the steel grade. However, the as-welded HSS cruciform joints can be more favorable and their fatigue lifetime is longer than the specimens made from NSS, if the stress range is below $100 \mathrm{MPa}$. The current study shows that the fatigue behavior of as-welded HSS details depends on the geometry of the investigated specimens and its fatigue lifetime can be larger in the small stress range region than for NSS specimens.
\end{abstract}

Keywords

fatigue, high strength steel, crack propagation, disc grinding, statistical analysis

\section{Introduction}

Nowadays, the reduction of the production costs of high strength steel (HSS) materials (S420 - S960) enabled the economic application of HSS in steel bridges. The advantages of the application of HSS come from the reduced self-weight of the structures. Due to the amount of used materials, the transporting and the construction cost can also be reduced, compared to structures made from normal strength steel (NSS; S235 - S355).

The most economical application field of HSS materials could be the long-span bridges or large span shell structures. Bridges are sensitive to fatigue. However, the fatigue design rules are not validated for welded HSS structures. Higher strength of the HSS can be exploited in the case of static design. However, the EN 1993-1-9 [1] and International Institute of Welding (IIW) recommendations [2] does not differentiate between the fatigue behavior of NSS and HSS structures. Thus, for cyclic loading there are no differences between the NSS and HSS structures in the design, which reduces its economic application.

This design rule is based on the previous experiments and studies, which investigated the fatigue behavior of specimens with different strength and geometries. These research results showed that the fatigue strength of the tested base material depends on the strength of the applied steel, and the obtained relationship is quasi-linear [3]. However, the fatigue strength of as-welded specimens is independent of the static strength of the analyzed steel grade, as shown in Fig. 1. This is the reason why the main part of current design recommendations neglect steel grade in fatigue design procedure.

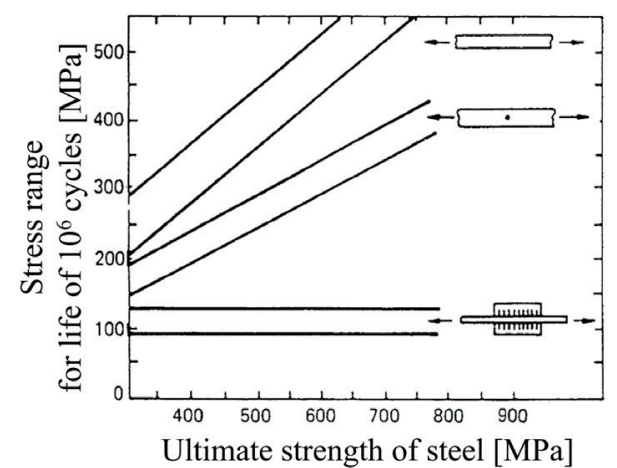

Fig. 1 Relationship between the fatigue strength and the ultimate tensile strength of steel [3] 


\section{Literature review}

The difference between fatigue properties of HSS and NSS materials is studied first and summarized in this Section (a steel material is considered as HSS if its yield strength is not lower than $355 \mathrm{MPa}$ [2]). The fatigue process of a steel specimen involves three different stages. The first one is the crack initiation phase or nucleation part. This phase terminates when the micro-crack increases and reaches the size of the macro-cracks, which is detectable and, in most cases, visible. The next phase of the fatigue lifetime is the stable crack propagation phase, when the evolved macro-crack grows until reaching a critical point, when the unstable crack propagation starts, which is a rushed and rigid phase. According to Maddox [3], favorable fatigue behavior of HSS base material belongs to the crack initiation part of the fatigue lifetime. The experimental results, which investigated the crack propagation rates of specimens from different steel grades, showed, that there is no significant difference between the crack propagation rates of NSS and HSS materials. This observation confirms the assumption that advantages of HSS base material in the fatigue behavior is based on the crack initiation phase.

The fatigue strength of notched and as-welded specimens is influenced by two main conditions [4]. On the one hand, the fatigue behavior of these detail types depends on the value of the mean stress of the cyclic load. Increasing mean stress decreases the fatigue strength. In the case of as-welded specimens, the high level of the mean stress comes from the tensile residual stresses due to welding. The tensile residual stresses can be approximately equal to $80-100 \%$ of the yield strength of the applied material [5]. Therefore, the mean stress for an as-welded specimen is always close to the yield strength. On the other hand, the crack initiation part of the welded specimens is negligible according to current theories. For notched specimens, the crack nucleation point is already appointed, and the crack grows from the tip of the notch. The notch can be considered as a macro crack, which propagates during the whole fatigue lifetime. Investigating the as-welded details, the undercuts and lack of fusions can behave as macro-cracks; thus, the crack initiation part of the fatigue lifetime becomes negligible.

The results of the previous experiments and research programs support the theory that the fatigue strength of the as-welded steel details is independent of the steel grade [6-9]. Anami and Miki [6] collected numerous test results for cruciform weld joints and re-analyzed the data, which are shown in Fig. 2. They showed that the reviewed

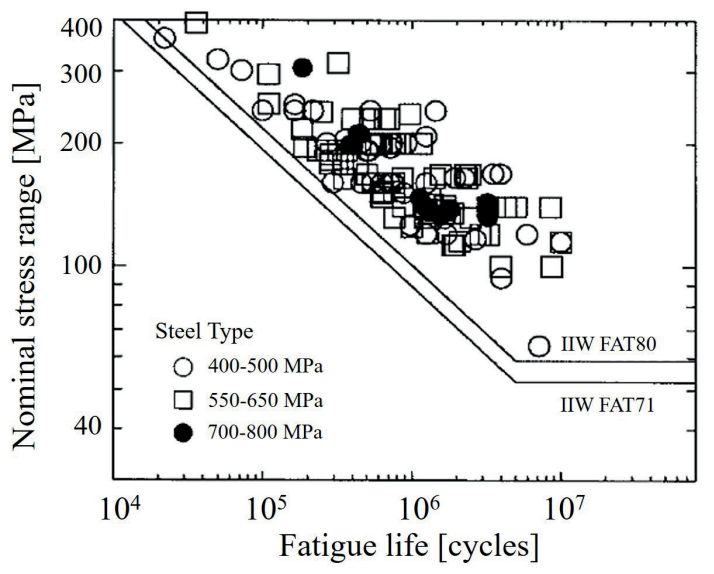

Fig. 2 Previous fatigue test results for cruciform joints [6]

experiments confirm the above introduced theory. However, it was recognized that the fatigue lifetime of the HSS specimens is not reached by the NSS specimens in the high stress range region. If the assumption that the $\mathrm{S}-\mathrm{N}$ curve is a straight line in the log-log system, is acceptable for HSS details as well, then this observation leads to the conclusion that the slope of S-N curve of HSS details does not equal to three. Consequently, the slope of the relevant $\mathrm{S}-\mathrm{N}$ curve should be larger than three. Therefore, the fatigue lifetime of HSS specimens should be more favorable in the lower stress range region. There are only a small number of previous test results regarding this stress range region found in the international literature. The main part of the previous experiments was carried out under loading with high stress range to limit the fatigue lifetime and the duration of the laboratory tests. Nevertheless, the representative stress ranges for bridge structures are below $100 \mathrm{MPa}$, therefore the fatigue behavior of the HSS specimens needs further research within this low stress amplitude range (high cycle range). In addition, the analyzed results come from different research programs using different test layouts, test environments and different loading and measuring systems, and different manufacturing methods, which makes the direct comparison of the fatigue test results more difficult.

On the other hand, the performed tests focused only on a small number of fatigue detail classes; thus, the present theory about the fatigue behavior of as-welded structural details is adaptable only on the investigated fatigue detail classes and its results cannot be generalized.

To analyze the results of the fatigue tests, the structural hot spot stress approach [10] or the effective notch stress approach could be applicable $[1,10]$ The result of finite element analysis is highly mesh sensitive, and in most cases, the fatigue-critical point is in an area of high strain 
gradients. The determined stresses depend on the type and size of the applied finite elements; thus a stress calculation approach is needed to obtain a relevant stress value. This calculation method is based on modelling and extrapolation techniques, which uses the determined stress values of pre-defined points of the finite element models [11].

The other applicable method is the effective notch stress approach, which is based on the computed highest elastic stress at the fatigue-critical point of the geometry [11]. This method was introduced by Radaj et al. [12]. The main idea of this approach is using a fictitious radius of $1 \mathrm{~mm}$ [2], where the stress singularity appears. The method can be used by $2 \mathrm{D}$ plane and $3 \mathrm{D}$ solid models. However, the 3D solid models are more favorable than the $2 \mathrm{D}$ ones. The difficulty of this method is that the accurate geometry of the investigated detail has to be modelled.

In the current study, the answers to the following questions are investigated. Is the fatigue strength of the as-welded structural details independent of the static strength of the applied material for all stress ranges? Is the answer to the previous question adaptable for all structural details? Is the crack initiation part of fatigue lifetime negligible for as-welded details? Is the crack propagation rate the same for NSS and HSS materials?

To investigate these problems an experimental research program is carried out at the Budapest University of Technology and Economics Department of Structural Engineering in Hungary to investigate the fatigue behavior of cruciform joints and gusset plate connections, which are frequently used for bridges in Hungary. The paper presents the results of this research program and tries to find the answers to the mentioned questions above.

\section{Description of the laboratory tests}

In the framework of the executed research program, two types of structural details are investigated. The experiments focused on the effect of the steel grade on the fatigue strength; therefore, the specimens are produced from NSS (S235) and HSS (S420) materials. On the other hand, the size effect is also studied; therefore, specimens are made with two different plate thicknesses $(10 \mathrm{~mm}$ and $18 \mathrm{~mm}$, which refers to the strength difference between the S235 and S420 steel grades). The ratio of the applied thicknesses is equal to the ratio of the yield strength of the applied NSS and HSS grades. The two tested details are the cruciform welded joint (X-type specimen), which was investigated in numerous previous papers [6-9], and the flange gusset joint (II-type specimen).
To increase the fatigue lifetime of welded joints, postweld treatment methods can be also applied. In this study, one of the simplest and most economic type of the weld treatments (disc grinding) is investigated. This treatment is a machining method, which improves the weld geometry; however, it does not generate favorable (compressive) residual stresses within the weld region. The measured fatigue lifetimes of the as-welded and disc grinded specimens are compared and evaluated based on the executed test program.

\subsection{Layout of the X-type specimens}

A total of 14 fatigue tests are conducted on cruciform joint specimens. Two different geometries of this structural detail are investigated within the current research program. The geometries and the dimensions of the X-10type specimens are shown in Fig. 3. These test specimens are produced from both NSS (S235) and HSS (S420) materials as well to be able to compare the fatigue behavior of NSS and HSS structures. The geometry of the test specimens and the manufacturing process are the same. The only difference is the applied steel grade. Specimens made with different thickness are also investigated and compared. The dimensions of the test specimens are shown in Figs. 3-4. These test specimens are produced only from NSS (S235) for investigation of the size effect on the fatigue lifetime.

The geometry of the test specimens can be seen in Fig. 5. The specimens are manufactured by using fillet welds with a weld throat size of 4 and $7 \mathrm{~mm}$, respectively. The loading machine is a Mohr-Federhaff Losenhausen HUS40 pulsator.

The applied load was a sinusoidal cyclic load with constant amplitude during the test. The minimum and the maximum applied loads are both tensions, thus the phenomenon of the crack closure did not have influence on the
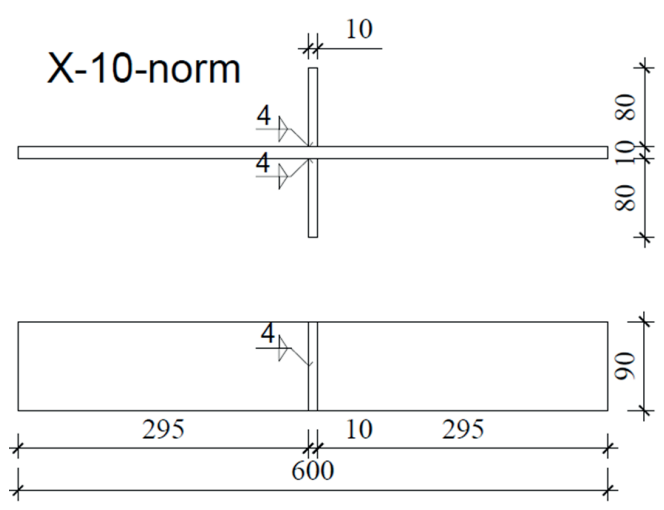

Fig. 3 Geometry of X-10 type specimens 

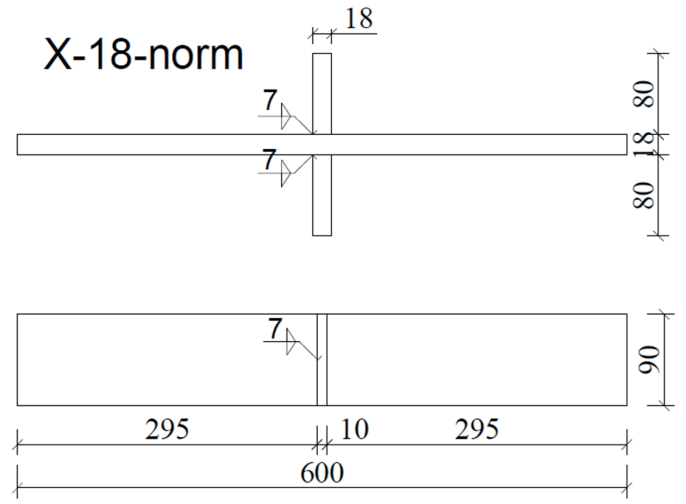

Fig. 4 Geometry of X-18 type specimens

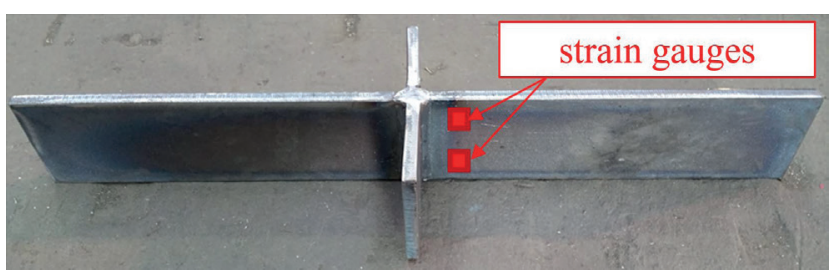

Fig. 5 Photo of an X-10 type specimen and the positions of strain gauges

test results. The minimum value of the cyclic load is $10 \mathrm{kN}$ in every case. The applied loading frequency is $6 \mathrm{~Hz}$. During the fatigue experiments, strains were measured close to the critical points of the structural detail (Fig. 5). In this case the critical fatigue point is the weld toe on the base plate. Two-two strain gauges are placed on all test specimens, their position is $15 \mathrm{~mm}$ from the longitudinal edge of the base plate and $50 \mathrm{~mm}$ from the toe of the fillet weld. The recording of the strains had a 10 -second-long interval in every 900 seconds. The end of an experiment is the failure of the specimen, which occurred by the crack propagation through the whole base plate. However, there were some run-out specimens, which did not fail. In that case the test was interrupted after 15 million cycles.

\subsection{Layout of the II-type specimens}

A total of 18 fatigue tests are conducted on a flange to gusset joint specimens. Two types of geometries are investigated, which are shown in Fig. 6 and Fig. 7. These test specimens are produced from NSS (S235) and from HSS (S420) material to compare the fatigue behavior. The test specimens with $18 \mathrm{~mm}$ thickness are produced only from NSS (S235) material for the investigation of the size effect.

The geometry of the test specimens and the positions of the strain gauges can be seen in Fig. 8. The loading method of these specimens is the same as the loading method of the cruciform joint specimens.

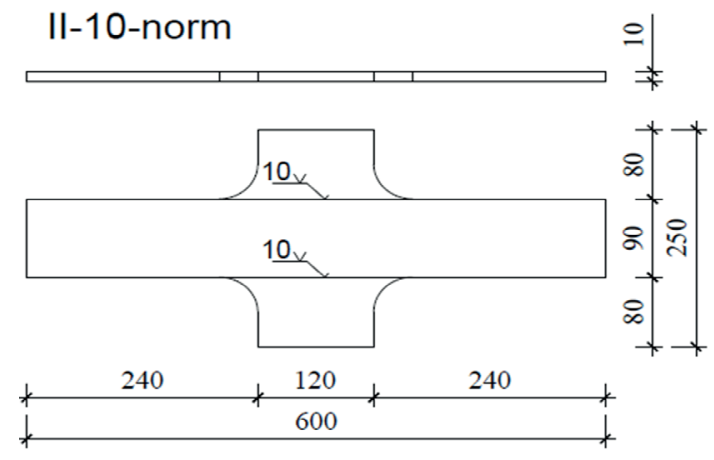

Fig. 6 Geometry of II-10 type specimens

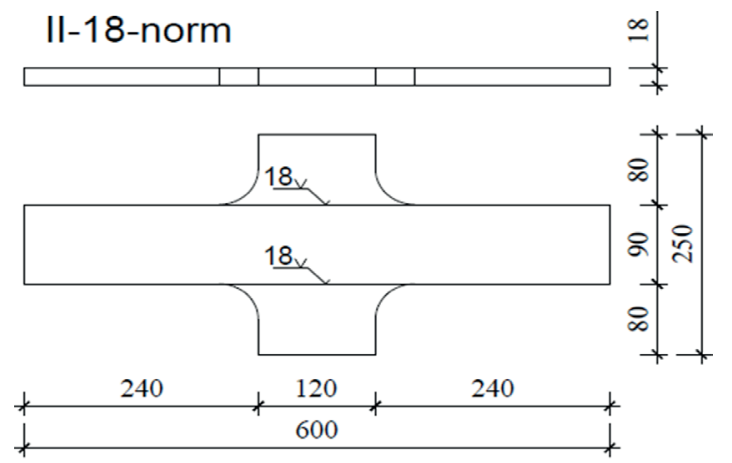

Fig. 7 Geometry of II-18 type specimens

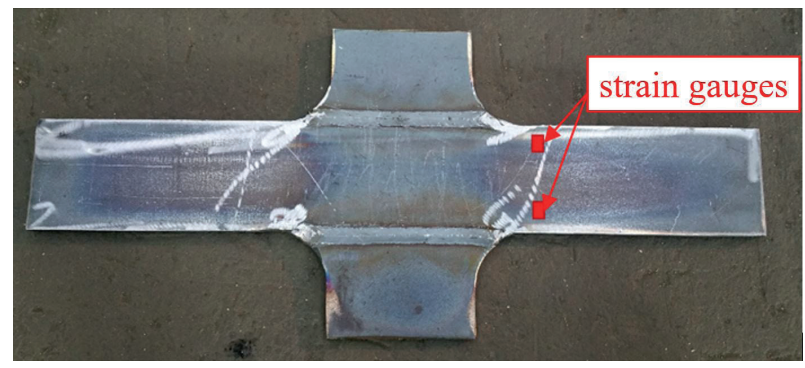

Fig. 8 Photo of an II-10 type specimen and the positions of strain gauges

\section{Results of the experiments}

The main results of the experiments are the fatigue lifetime of the test specimens by applying different stress ranges to be able to determine the relevant S-N diagram for all the analyzed structural details. Moreover, important information can be taken from the crack pattern of the tested specimens. Analyzing them, the crack initiation point and the route of the crack propagation are determined. Finally, the measured strain data by the strain gauges show the change of the stress range close to the weld toes, which are also evaluated for all test specimens.

\subsection{Results of the X-type test specimens}

The results of the experiments are summarized in Table 1. The table contains the number of the test specimens, the applied material and geometrical properties, the applied 
load and stress ranges, and the measured fatigue life cycles. The typical observed failure mode, the fatigue crack pattern and the measured stresses during the lifetime are presented in Fig. 9 and Fig. 10.

Table 1 Parameters and results of the experiments of X-type specimens

\begin{tabular}{|c|c|c|c|c|c|}
\hline $\begin{array}{l}\text { No. of } \\
\text { specimen }\end{array}$ & Material & $\begin{array}{c}t \\
{[\mathrm{~mm}]}\end{array}$ & $\begin{array}{c}\Delta F \\
{[\mathrm{kN}]}\end{array}$ & $\begin{array}{c}S \\
{\left[\mathrm{~N} / \mathrm{mm}^{2}\right]}\end{array}$ & $\begin{array}{c}N \\
\text { [cycles] }\end{array}$ \\
\hline 1 & S420 & 10 & 90 & 100 & 6327900 \\
\hline 2 & $\mathrm{~S} 235$ & 10 & 90 & 100 & 1821100 \\
\hline 3 & S420 & 10 & 135 & 150 & 538000 \\
\hline 4 & S420 & 10 & 110 & 122 & 1313200 \\
\hline 13 & S235 & 10 & 110 & 122 & 839900 \\
\hline 15 & $\mathrm{~S} 235$ & 10 & 130 & 144 & 599410 \\
\hline 16 & S235 & 18 & 61 & 38 & 3300000 \\
\hline 17 & $\mathrm{~S} 235$ & 18 & 220 & 136 & 286900 \\
\hline 18 & S235 & 18 & 160 & 99 & 1239900 \\
\hline 30 & S420 & 10 & 100 & 111 & 780700 \\
\hline 32 & S235 & 10 & 120 & 133 & 566400 \\
\hline 33 & S420 & 10 & 120 & 133 & 671000 \\
\hline 34 & S235 & 10 & 100 & 111 & 919400 \\
\hline 35 & S420 & 10 & 100 & 111 & 1194200 \\
\hline
\end{tabular}

$\Delta F$ : force range; $S$ : stress range; $N$ : number of cycles to failure

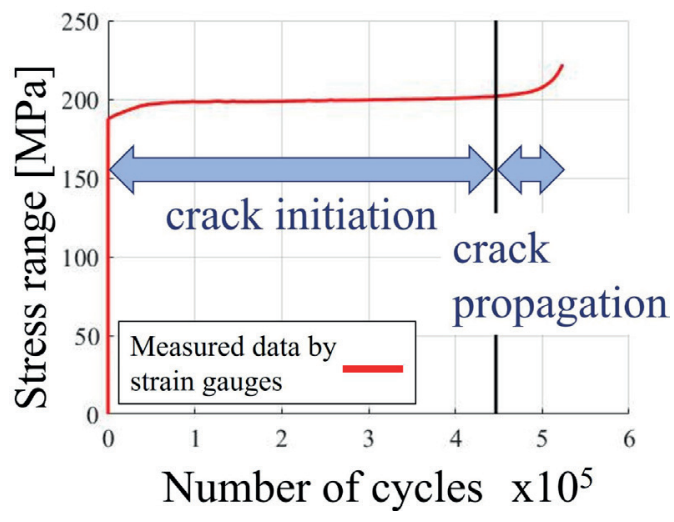

Fig. 9 Fracture surface of an X-type specimen

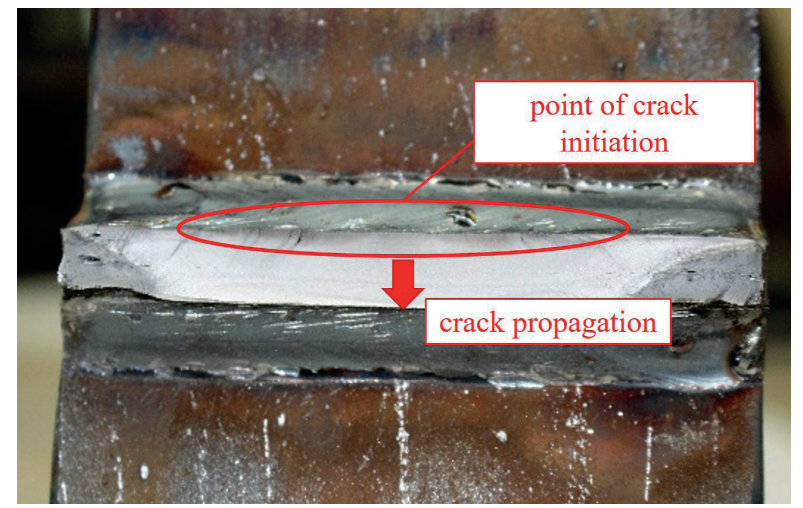

Fig. 10 Measured stress range of an X-type specimen (No. 3 specimen)
The fracture surfaces (Fig. 9) show that the crack initiates in the base plate close to the weld toe, in the middle of the plate. The crack propagates through the thickness of the base plate till it reaches the opposite edge. After that the crack grows from the middle to the edges of the plate. The failure point can easily be recognized from the rough texture of the crack surface.

According to the measured stress amplitudes, the crack initiation part is found dominant in the fatigue lifetime of the X-type specimens (Fig. 10). The value of the measured stress range is almost constant during the main part of the tests, except a short period at the end of the lifetime. The final part of the lifetime is the crack propagation region. Thus the measured stress range varies close to the weld toe [13].

From the fatigue test results, the experimental S-N curves of the analyzed structural details are plotted in Figs. 11-12. To investigate the real fatigue behavior of these structural details, a mathematical statistical analysis becomes necessary, which is presented in Section 6.

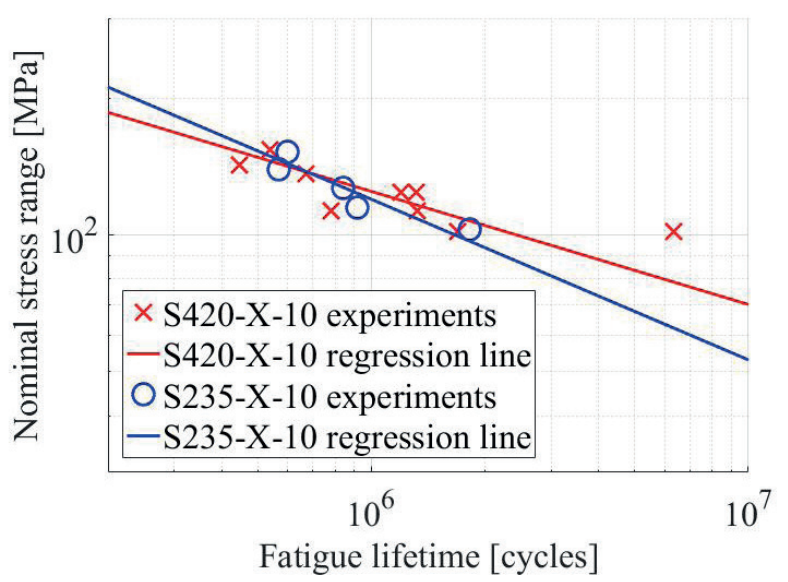

Fig. 11 Experimental S-N diagram of S235 and S420 X-type specimens

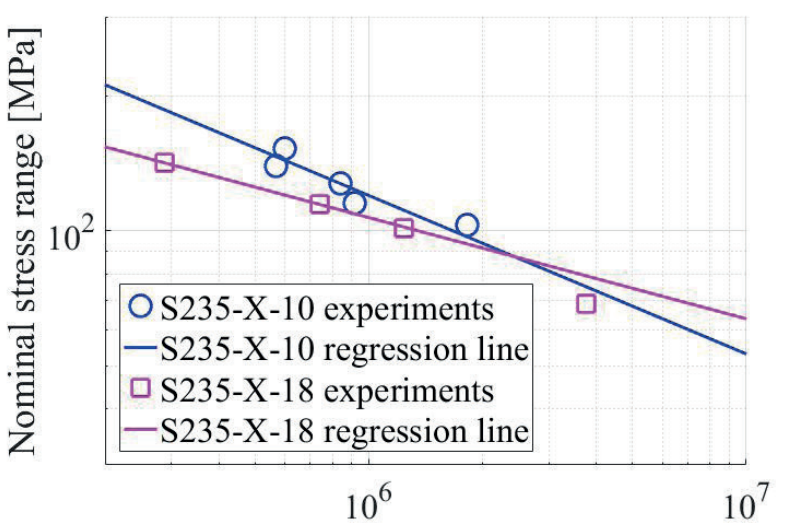

Fatigue lifetime [cycles]

Fig. 12 Experimental S-N diagram of S235 X-10 and X-18 specimens 
Analyzing the S-N diagrams of S235-X-10 and S235-X-18 specimens (Fig. 12), it can be observed that all results, which belongs to the specimens with thickness of $18 \mathrm{~mm}$, are below the results of the thinner specimens. However, the size effect is taken account only for details, where the thickness of elements is greater than $25 \mathrm{~mm}$. The diagrams show that this effect should be taken into consideration for thinner plates as well.

\subsection{Results of the II-type test specimens}

The results of the experiments are summarized in Table 2. The table contains: the number of test specimens, the applied material and geometrical properties, the applied load and stress ranges and the measured fatigue life cycles. The typical failure mode, the fatigue crack pattern, and the measured stresses during the lifetime are presented in Fig. 13 and Fig. 14.

Analyzing the fracture surface of the specimens, it can be observed that the crack initiation point is always located at the end of the weld (Fig. 13). The crack is a through-thickness crack, and it propagated perpendicular to the longitudinal edge of the base plate. The failure point is on the opposite side of the base plate, which can be seen from the rough part of the crack surface. From the measured strain values the stress ranges could be calculated at the positions of the strain gauges. Analyzing these values during the whole fatigue lifetime (Fig. 14), the border between the

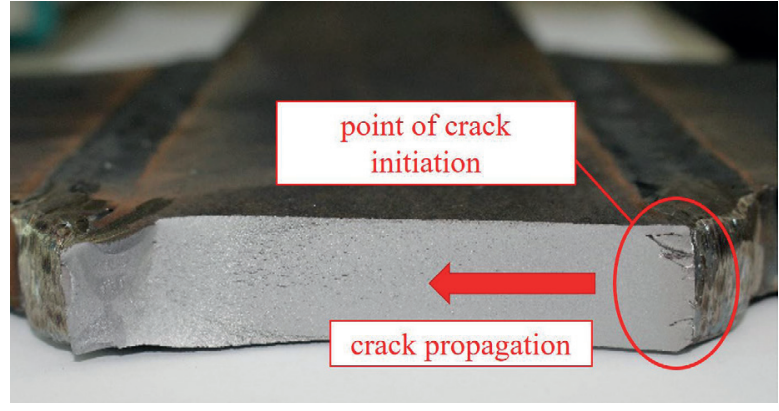

Fig. 13 Fracture surface of an II-type specimen

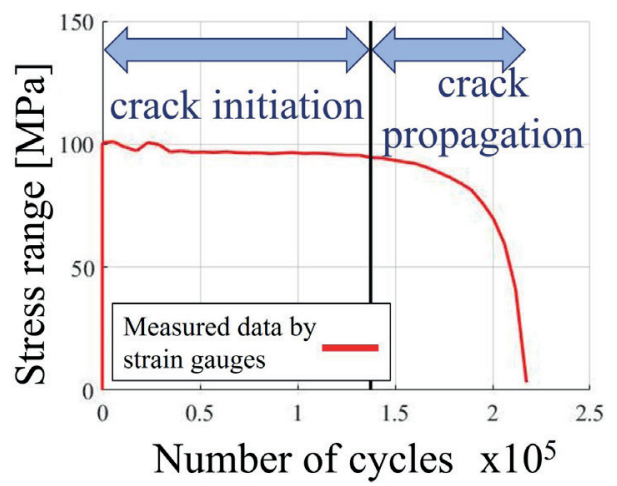

Fig. 14 Measured stress range of an II-type specimen (No. 1 specimen) crack initiation and the crack propagation region can be observed [13]. The stress range-load cycle diagrams show, that the crack nucleation and the crack propagation part of the lifetime are also dominant and have significant impact on the fatigue behavior of the test specimens.

Table 2 Parameters and results of the experiments of II-type specimens

\begin{tabular}{|c|c|c|c|c|c|c|}
\hline No. of specimen & Material & Post weld treatment & $t[\mathrm{~mm}]$ & $\Delta F[\mathrm{kN}]$ & $S\left[\mathrm{~N} / \mathrm{mm}^{2}\right]$ & $N$ [cycles] \\
\hline 5 & $\mathrm{~S} 235$ & none & 10 & 90 & 100 & 210100 \\
\hline 6 & S235 & none & 10 & 60 & 67 & 270700 \\
\hline 7 & S235 & disc grin. & 10 & 60 & 67 & 9136500 \\
\hline 8 & S235 & disc grin. & 10 & 90 & 100 & 672400 \\
\hline 9 & S420 & disc grin. & 10 & 90 & 100 & 646600 \\
\hline 10 & S420 & none & 10 & 70 & 78 & 548900 \\
\hline 11 & S420 & none & 10 & 90 & 100 & 275200 \\
\hline 12 & S420 & disc grin. & 10 & 70 & 78 & 530800 \\
\hline 14 & S420 & disc grin. & 10 & 60 & 67 & n.f. \\
\hline 19 & S235 & none & 18 & 160 & 99 & 535700 \\
\hline 20 & S235 & none & 18 & 140 & 86 & 442200 \\
\hline 21 & S235 & none & 18 & 120 & 74 & 519200 \\
\hline 22 & $\mathrm{~S} 235$ & disc grin. & 18 & 160 & 99 & $15 \mathrm{E}+6$ \\
\hline 23 & S235 & disc grin. & 18 & 220 & 136 & 1310000 \\
\hline 26 & S235 & none & 10 & 60 & 67 & 1121400 \\
\hline 27 & $\mathrm{~S} 235$ & none & 10 & 110 & 122 & 131700 \\
\hline 28 & $\mathrm{~S} 235$ & none & 10 & 50 & 56 & 1300900 \\
\hline 29 & S420 & none & 10 & 50 & 56 & 1019600 \\
\hline
\end{tabular}

$\Delta F$ : force range; $S$ : stress range; $N$ : number of cycles to failure 
From the fatigue test results, the experimental S-N curves are plotted on Fig. 15 and Fig. 16. According to these diagrams, the slopes of the S-N curves cannot be compared by only the investigation of the figures because of the scatter of the test results. To investigate the real fatigue behavior of these structural details, a mathematical statistical analysis becomes necessary, presented in Section 6 .

Analyzing the S-N diagrams of S235-II-10 and S235-II-18 specimens (Fig. 16), it can be observed that all test results lie more or less on the same line. It is in good agreement with the standards and recommendations, the size effect is taken account only for details, where the thickness of elements is greater than $25 \mathrm{~mm}$. The diagrams show that this assumption is correct for flange-gusset detail types.

Investigating the effect of disc grinding, it can be observed that there is a significant difference between the S-N diagrams of as-welded and disc grinded specimens. The ratio between fatigue strength of as-welded and disc ground specimens is approximately 1.5 (Table 3), which value is in good agreement with the modifier factor, recommended by IIW. According to the test results, the IIW recommendation can be applied for calculating the fatigue lifetime of disc ground gusset-flange structural details.

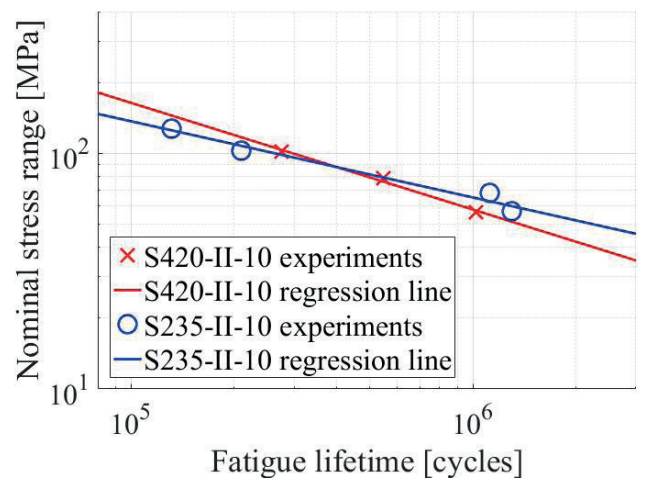

Fig. 15 Experimental S-N diagram of S235 and S420 II-type specimens

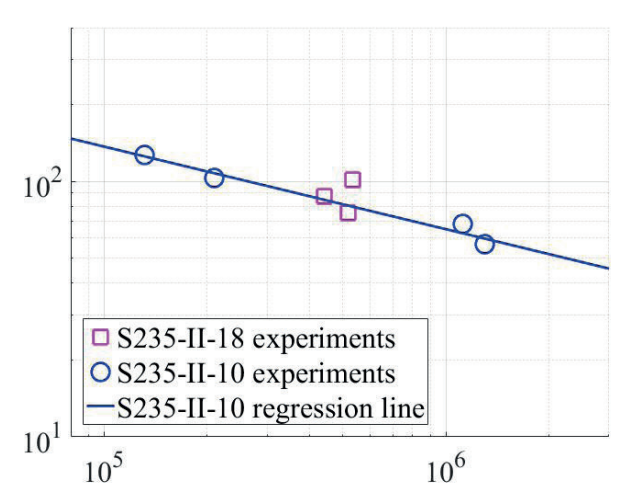

Fig. 16 Experimental S-N diagram of S235 II-10 and II-18 specimens
Table 3 Experimental fatigue strength increase factors for disc ground specimens

\begin{tabular}{cccc}
\hline $\begin{array}{c}\text { Type of } \\
\text { specimens }\end{array}$ & $\begin{array}{c}\text { Fatigue strength } \\
\text { of as-welded } \\
\text { specimens [MPa] }\end{array}$ & $\begin{array}{c}\text { Fatigue strength } \\
\text { of disc ground } \\
\text { specimens [MPa] }\end{array}$ & $\begin{array}{c}\text { Increase } \\
\text { factor }\end{array}$ \\
\hline II-10-S235 & 125.91 & 206.16 & 1.64 \\
II-10-S420 & 123.28 & 186.74 & 1.51 \\
\hline
\end{tabular}

The fatigue strengths belong to the fatigue lifetime, which equals to $2 \times 10^{6}$.

\section{Numeric modelling}

The results of the experiments can be analyzed by nominal, hot spot and effective notch stresses as well. One of the main aims of the research program is to compare the fatigue behavior of the two investigated structural details and to compare the differences depending on the steel grade.

Applying the hot spot stress method, the geometry of the weld is modelled, the maximum value of the stress can be observed at the weld toes and other singularity point of the geometry. In these cases, the calculated value of the stress is infinite at these points. The hot spot stress can be calculated from these models. At predefined points, the stresses are determined and a linear or quadratic extrapolation is used for calculating the stress at the singularity points. The positions of these predefined points of model calculations depend on the geometry of the investigated detail and the position of the analyzed weld, as shown in Fig. 17. There are seven different hot spot fatigue classes depending on the position of the analyzed singularity point. The X-type (cruciform) details belong to the hot-spot fatigue class 100 and the II-type (flange gusset) details has no hot-spot fatigue class. Therefore, the two investigated structural details cannot be plotted in the same system. The two detail types cannot be investigated together. Thus, this method is not suitable for comparing the fatigue behavior of cruciform and flange gusset joints.

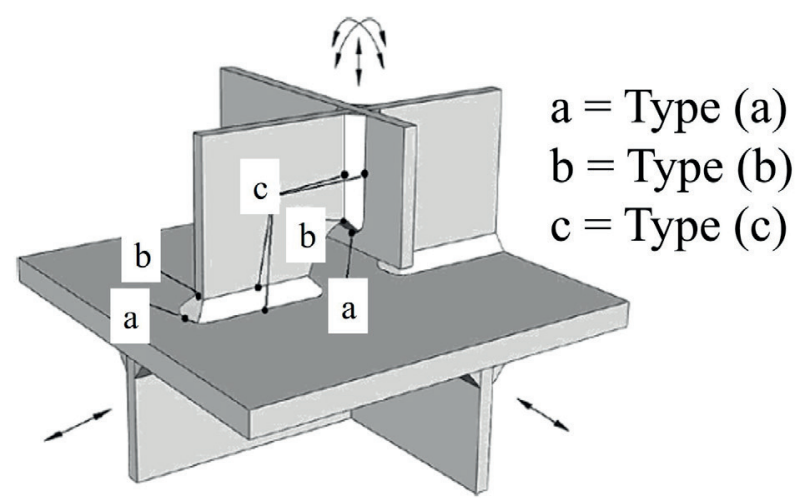

Fig. 17 Three types of fatigue-critical hot-spot point at the weld toes [11] 
The other adaptable method is the effective notch stress method. In this case the quasi-real geometry of the details is modelled with welds, offcuts and little discontinuities. The singularity points are eliminated by applying rounding in the critical regions. This method makes possible to investigate the test results of the two details in a common $\mathrm{S}-\mathrm{N}$ coordinate system, because the effective notch stress method has only one fatigue class, which applies to all geometry and all steel grades.

\subsection{FEM model for effective notch stress method}

Therefore, the effective notch method has been chosen to analyze together the test results of both structural details. This method is used for determining the total stress at the root of a notch. The real weld contour is replaced by an effective one. Thus the scatter of weld geometry can be taken into account [2]. The recommended effective notch root radius is $r=1 \mathrm{~mm}$. This method is limited to thicknesses above $5 \mathrm{~mm}$. However, in this research program the minimum thickness is $10 \mathrm{~mm}$ for all of the investigated details. Thus, the method is applicable.

The numerical model of the investigated specimens is developed in ANSYS 17.2. The parameters of the model correspond to the recommendations of the IIW [2]. The model is based on a solid model using twenty-node structural solid element. The effective notch root and weld toe radius is the recommended $r=1 \mathrm{~mm}$. The element size is the recommended $0.15 \mathrm{~mm}$ in the surroundings of the critical fatigue points, and $0.5 \mathrm{~mm}$ far from the critical points.

The symmetry of the details is used for reducing the number of the applied elements. In the case of the X-type and II-type specimens, the one eighth of the full specimen was modelled (Figs. 18-21). The supports of the model correspond to the symmetry conditions.

The model is loaded by an axial uniformly distributed load. The sum of the loading force is $100 \mathrm{kN}$ in every case. The executed calculations are linear elastic calculations. Therefore, the stresses from all of the applied load ranges of the experiments can be calculated from the model with $100 \mathrm{kN}$ loading. To calculate the current stress values, the stress value from the model with $100 \mathrm{kN}$ loading is multiplied with the ratio of the current loading range to 100 $\mathrm{kN}$. The 1st principal stress (Figs. 22-23) was determined in the critical fatigue point (the weld toe on the surface of base plate for X-type specimens (Fig. 18); the end of the weld for II-type specimens (Fig. 19)), and this value was used for determining the experimental S-N curves.

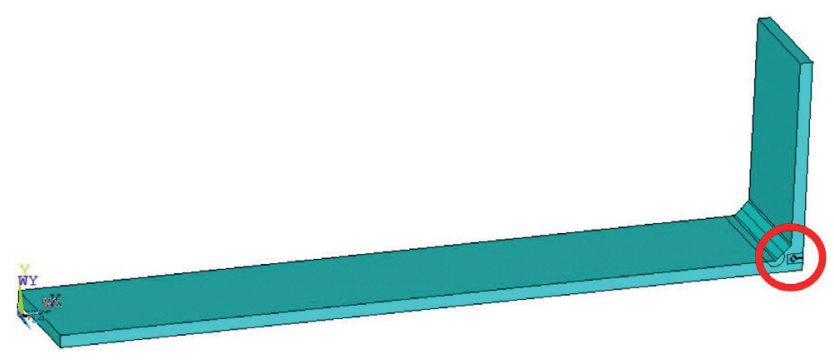

Fig. 18 Numeric model of X-type specimen

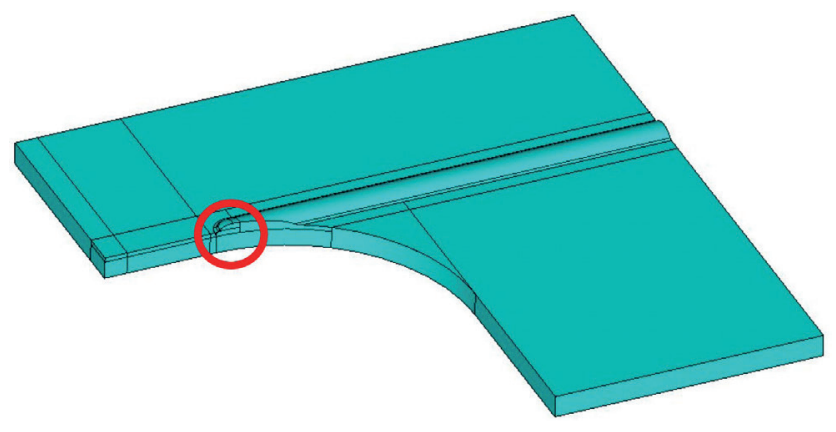

Fig. 19 Numeric model of II-type specimen

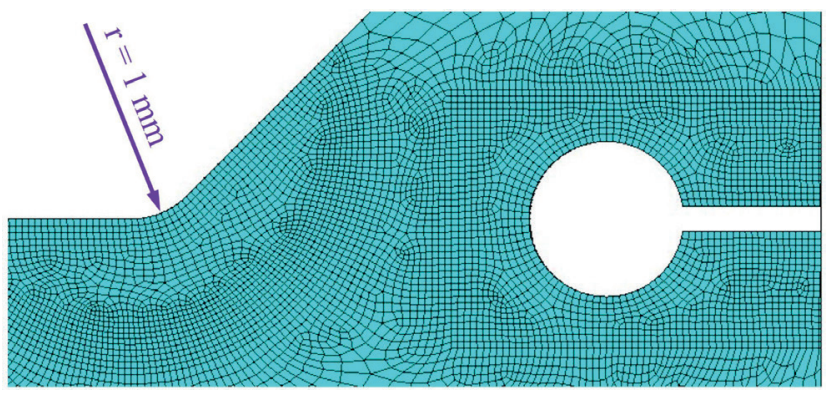

Fig. 20 Model geometry and finite element mesh of X-type specimen in the weld toe (singed in Fig. 18)

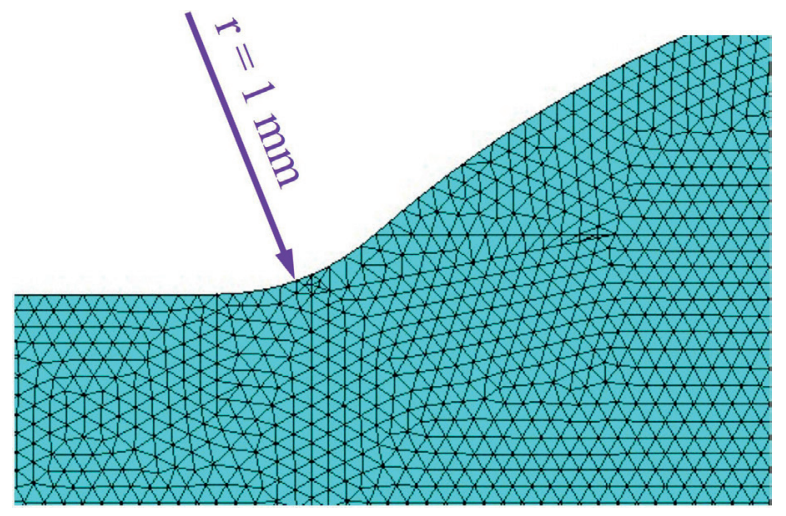

Fig. 21 Model geometry finite element mesh of II type specimen in the end of the weld (singed in Fig. 19)

The calculated $1^{\text {st }}$ principal stresses are paired to the measured fatigue life of the test specimens. The experimental S-N curves are fitted to the plotted points of the test results with a slope of 3 in a log-log system. 


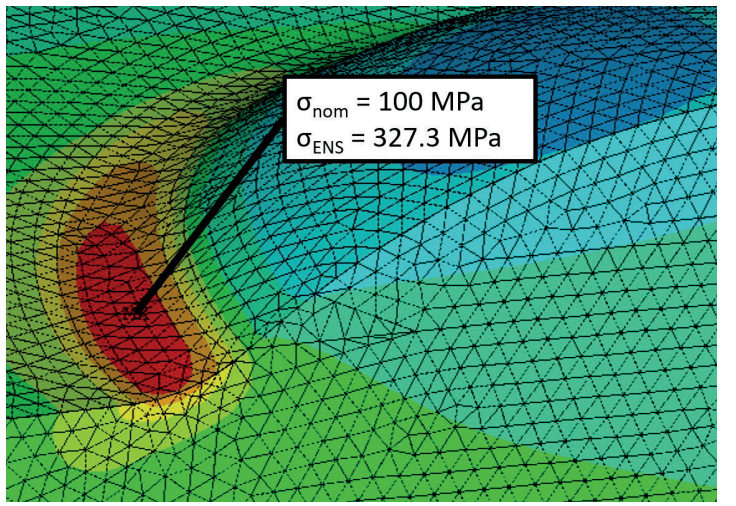

Fig. 22 Nominal (nom) and $1^{\text {st }}$ principal stress (ENS) of the X-type specimen in the critical point

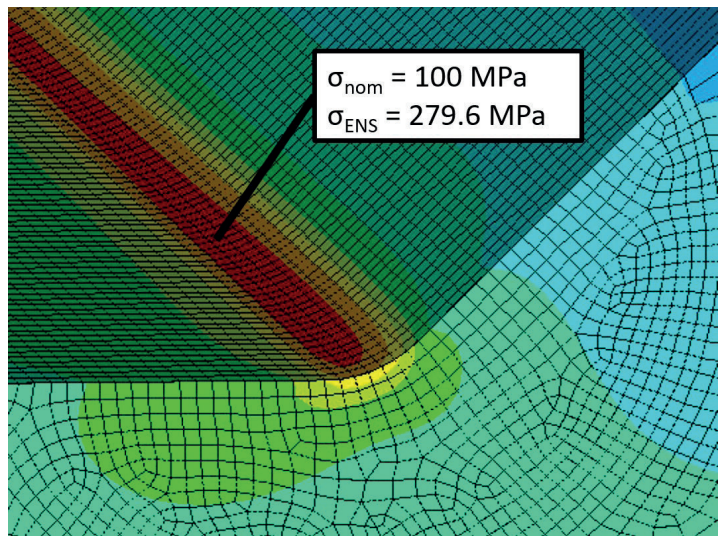

Fig. 23 Nominal (nom) and $1^{\text {st }}$ principal stress (ENS) of the II-type specimen in the critical point

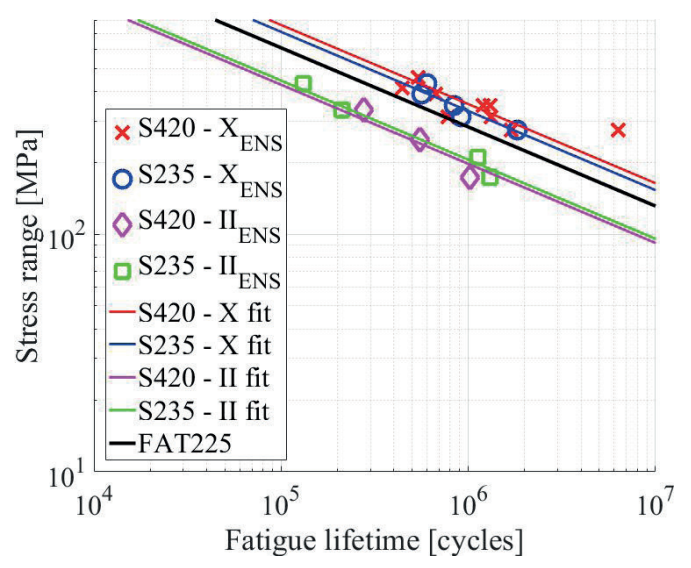

Fig. 24 Experimental S-N curves of different types of specimens and the standard S-N curve for ENS approach

Investigating the plotted points of the experiments it can be recognized that the results of these two types of structural details are not from a common data set (Fig. 24). To analyze the effect of HSS materials on the fatigue behavior generally, it is necessary that the base behavior (NSS) will be the same for every investigated detail. It can be a solution of this problem if the modelling parameters are slightly changed. By varying the root radius, data sets of the two different structural details can be made common. The sameness of these two data sets can be verified by the tools of mathematical statistics. It was assumed that the slopes of the experimental S-N curves of NSS specimens are equal to 3 . If the intercept of the experimental S-N curves of the two details is statistically the same, then the data sets can be considered identical.

\subsection{Statistical analysis of the modeling parameters of FEM}

For the mathematical statistical analysis, the two sample Student's t-test can be applied if the estimated standard deviations of the two regression lines are the same. If the standard deviations $(\sigma)$ are significantly different, then the two sample Welch-test can be applied, which is similar to the previous test. However, the calculation method of the DOF-s $(f)$ are different. Before investigating the estimated standard deviations, the basic statistical parameters of the data sets are determined according to Eq. (1) and Eq. (2).

$$
\begin{aligned}
& \sigma_{\log S, \log N}=\sqrt{\frac{1}{n-2}\left[\sum(\log N-\overline{\log N})^{2}-\frac{\left[\sum(\log S-\overline{\log S})(\log N-\overline{\log N})\right]^{2}}{\sum(\log S-\overline{\log S})^{2}}\right]} \\
& \sigma_{\log S}=\sqrt{\frac{\sum(\log S-\overline{\log S})^{2}}{n-1}}
\end{aligned}
$$

After calculating the estimated standard deviations of $\log S$ and the residuals of the regressions, the standard deviations of the residuals of the paired data sets are inspected if they are significantly different, or not. For this investigation, the statistical $F$-test is recommended in the literature $[14,15]$. According to the test, if the ratio of the standard deviations of the residuals are less than a calculated $F$ value (Eq. (3)), then the standard deviations can be considered identical.

$$
\frac{\sigma_{\log S, \log N, 1}}{\sigma_{\log S, \log N, 2}} \leq F_{f_{1}}^{f_{2}},
$$

where $\sigma_{\log S, \log N, 1}>\sigma_{\log S, \log N, 2}$ and $f_{k}=n_{k}-2$

Calculating the standard deviations of the residuals, and applying the $F$-test, all compared data set shows a good agreement regarding the standard deviations. The results of the $F$-tests are shown in Table 4.

- $H_{0, i j}$ : the standard deviations of $i$ and $j$ data sets are significantly the same.

- $H_{1, i j}$ : the standard deviations of $i$ and $j$ data sets are significantly not the same. 
Table 4 F-test of the standard deviations of the residuals

\begin{tabular}{lccccc}
\hline Compared data sets & $\begin{array}{l}\sigma_{\log , \log N, i} \\
\sigma_{\log , \log N, j}\end{array}$ & $f_{i}$ & $f_{j}$ & $F_{f_{i}}^{f_{j}}$ & $t_{c r i t}$ \\
\hline $\begin{array}{l}\text { S420-X-10 (1) vs. } \\
\text { S235-X-10 (2) }\end{array}$ & 1.939 & 8 & 3 & 11 & 1.796 \\
$\begin{array}{l}\text { S235-X-10 (2) vs. } \\
\text { S235-X-18 (3) }\end{array}$ & 0.719 & 3 & 3 & 6 & 1.943 \\
$\begin{array}{l}\text { S420-II-10 (4) vs. } \\
\text { S235-II-10 (5) }\end{array}$ & 0.467 & 1 & 2 & 3 & 2.353 \\
\hline $\begin{array}{l}\alpha=0.10 \\
*\end{array}$ & & & & & \\
In parenthesis the indices of the different types, used in the followings.
\end{tabular}

The standard deviations of the residuals are consistent on the $\alpha=0.10$ significance level. Thus, the Student's $\mathrm{t}$-test is applicable. Using this type of tests, the similarity of the intercept of the regression $\operatorname{lines}(\log \alpha)$ is investigated. The null hypothesis of the test will be the case when the two compared intercepts are equal, thus the difference between the two intercepts equals to zero in an $\alpha$ level of significance.

- $H_{0, i j}:$ the intercept of the S-N curves of $i$ and $j$ data sets are significantly the same

- $H_{1, i j}$ : the intercept of the S-N curves of $i$ and $j$ data sets are significantly not the same

To facilitate the further calculations, the method of pooled error variance is used [14]. Firstly the pooled error variance $\left(\sigma_{\text {res }}\right)$ is determined, which is the pooled value of the error variances, weighing by their DOF-s (Eq.(4)).

$\sigma_{\text {res }}^{2}=\frac{\left(n_{i}-2\right) \sigma_{\log S, \log N, i}^{2}+\left(n_{j}-2\right) \sigma_{\log , \log N, j}^{2}}{\left(n_{i}-2\right)+\left(n_{j}-2\right)}$

Knowing the estimated standard deviations of the intercept differences, the test statistics $(t)$ are calculated by Eq. (5), and the test is performed.

$t_{i j}=\frac{\left|\log a_{i}-\log a_{j}\right|}{\sigma_{\log a, i-\log a, j}}$

The t-tests are performed on the $\alpha=0.10$ significance level; the results of the tests are shown on Figs. 25-26. According to the investigations, it can be declared that applying the recommended parameters the results of the studied details cannot be considered as a common data set. Thus, changing the modelling parameters is necessary to investigate the two structural details simultaneously. Modifying the weld toe radius is a good choice to solve this problem. Applying an $r=0.5 \mathrm{~mm}$, it can be shown that the intercepts of experimental S-N curves of the investigated detail types are statistically the same (Fig. 27). Thus, the comparison of the fatigue behavior of details is doable.

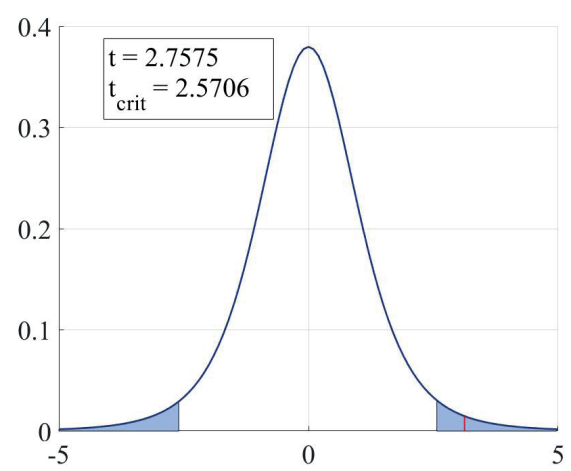

Fig. $25 \mathrm{t}$-test for radius equals to $1 \mathrm{~mm}$

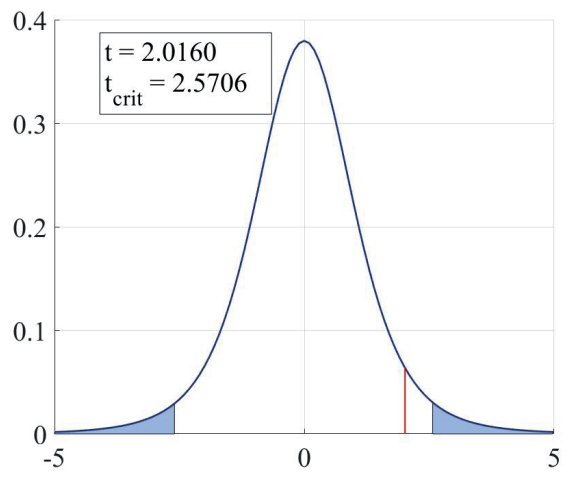

Fig. 26 t-test for radius equals to $0.5 \mathrm{~mm}$

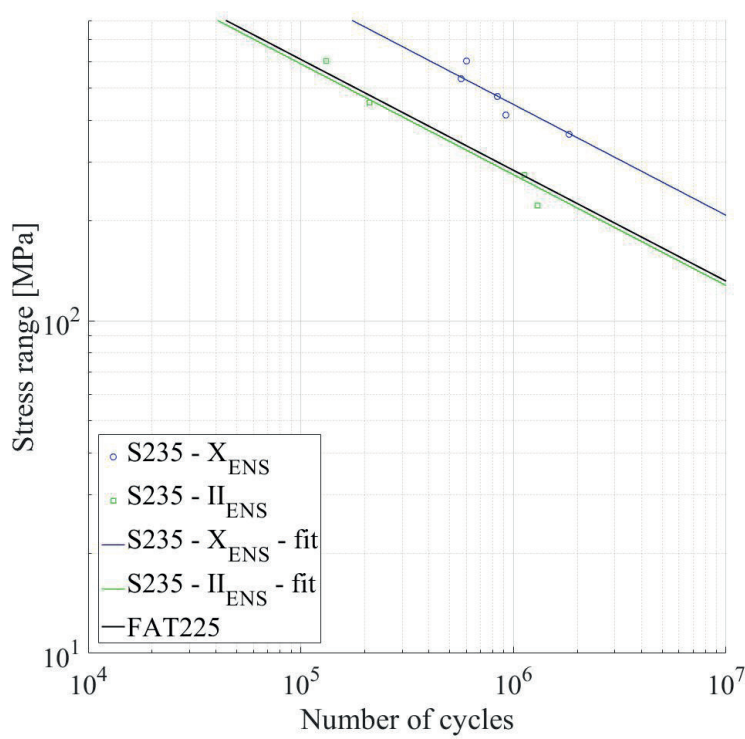

Fig. 27 Experimental S-N curves of different types of specimens with $r=0.5 \mathrm{~mm}$ of fictitious radius

\section{Evaluation of the test results}

The test results of the investigated structural details can be compared in a common S-N system. The parameters of the $\mathrm{S}-\mathrm{N}$ curves are determined by the method of least squares. In a log-log system the S-N curves are linear. Thus, this linear regression can be applicable. The analysis of the slopes of regression lines are necessary to get to know the 
fatigue behavior of HSS details. If the obtained S-N curve slopes are identical with the slope of the S-N curves $(m=3)$ of the NSS structures, then the well-known fatigue classes can be used for design of the HSS details as well. However, if the slopes of HSS S-N curves are different from the NSS ones, the fatigue behavior of HSS specimens differs from the NSS specimens. Investigating the effect of the uncertainties of the fatigue tests, mathematical statistical analysis is applied to compare the calculated S-N curve slopes.

\subsection{Statistical analysis of the slopes of $\mathrm{S}-\mathrm{N}$ curves}

The experimental S-N curves based on the results of the modified numerical model are compared and the slope of the relevant $\mathrm{S}-\mathrm{N}$ curve is determined and statistically evaluated. According to the previous F-test, Student's $t$-test can be applied. In this case, the null hypothesis of the test is the equality of the two compared slopes. Thus, the difference between the two slopes equals to zero in an $\alpha$ level of significance. The calculations of the standard deviation of the difference of the slopes and the $t$-statistics differ from the determination of $t$-statistic of intercepts. Modifying the previously introduced equations, the missing parameters are determined by Eq. (6) and Eq. (7).

$\sigma_{m i-m j}=\sigma_{r e s} \sqrt{\frac{1}{\sigma_{\log S, i}^{2}\left(n_{i}-1\right)}+\frac{1}{\sigma_{\log S, j}^{2}\left(n_{j}-1\right)}}$

$t_{i j}=\frac{\left|m_{i}-m_{j}\right|}{\sigma_{m i-m j}}$

The t-tests are performed on the $\alpha=0.10$ significance level. The results of the tests are shown in Table 5 and in Figs. 28-30. According to the statistical evaluation, it can be stated that the fatigue behavior of the welded cruciform high strength steel specimens differs from the normal strength steel specimens. The fatigue lifetime of the HSS specimens are greater in the lower stress range region than the NSS specimens.

Table 5 t-test of the standard deviations of the residuals

\begin{tabular}{|c|c|c|c|c|c|c|}
\hline Compared data sets & $t_{i j}$ & $f_{i}$ & $f_{j}$ & $v_{i j}$ & $t_{c r i t}$ & $H_{0}$ \\
\hline $\begin{array}{l}\text { S420-X-10 (1) vs. } \\
\text { S235-X-10 (2) }\end{array}$ & 1.939 & 8 & 3 & 11 & 1.796 & false \\
\hline $\begin{array}{l}\text { S235-X-10 (2) vs. } \\
\text { S235-X-18 (3) }\end{array}$ & 0.719 & 3 & 3 & 6 & 1.943 & true \\
\hline $\begin{array}{l}\text { S420-II-10 (4) vs. } \\
\text { S235-II-10 (5) }\end{array}$ & 0.467 & 1 & 2 & 3 & 2.353 & true \\
\hline
\end{tabular}

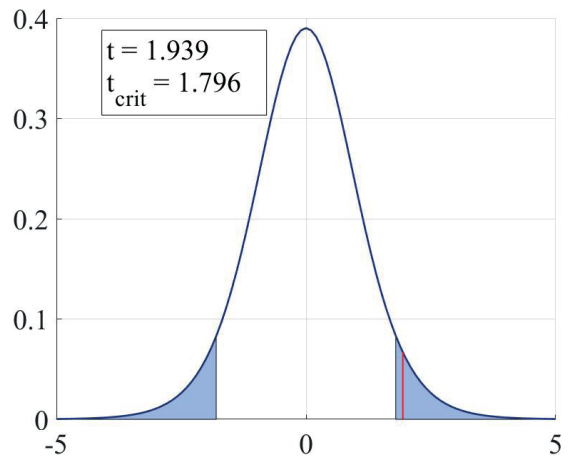

Fig. 28 Student's t-test of the slopes of S-N curves of S420-X-10 vs. S235-X-10 specimens

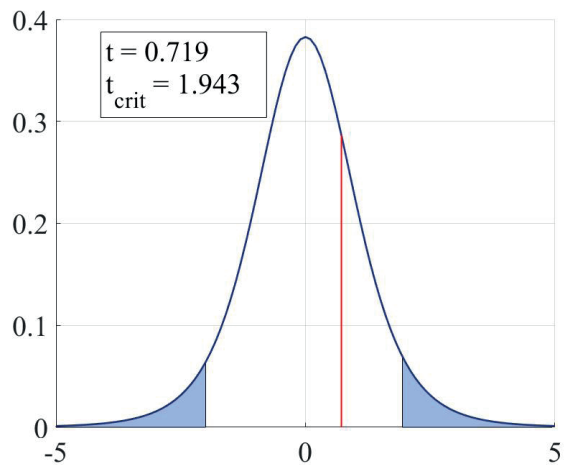

Fig. 29 Student's t-test of the slopes of S-N curves of S235-X-10 vs. S235-X-18 specimens

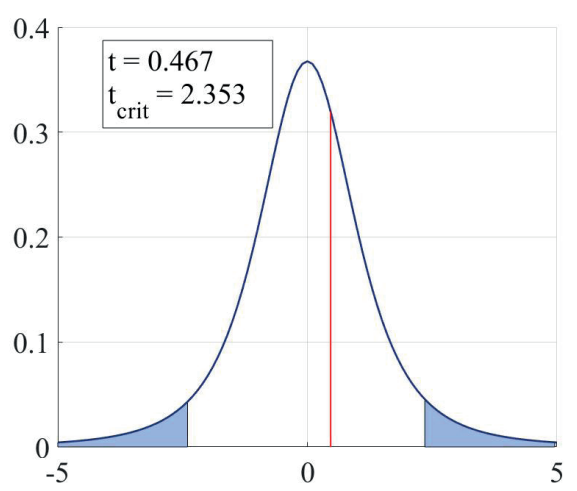

Fig. 30 Student's t-test of the slopes of S-N curves of S420-II-10 vs. S235-II-10 specimens

The slope of the experimental S-N curve of this type of specimen is approximately 4; thus, applying HSS material in the stress range region below $100 \mathrm{MPa}$ can be more favorable from fatigue point of view. On the other hand, the flange gusset joints do not show this auspicious property. Comparing the fatigue lifetimes of HSS and NSS specimens, it can be observed in this case that plotted results fit on the same S-N curve. Thus, there is no significant difference between the fatigue behavior of NSS and HSS as-welded specimens. 


\section{Conclusions}

In the framework of the executed research program the fatigue behavior of two typical structural details used in Hungarian bridges are studied and the fatigue properties of NSS and HSS specimens are compared. Based on the executed experimental research program and statistical evaluation the following conclusions are drawn:

Test results on flange gusset details confirmed the assumption that the fatigue strength of an as-welded steel structural detail is independent of the steel grade. Test results on cruciform specimens show that HSS material has a more favorable fatigue behavior than the NSS in the stress range region below $100 \mathrm{MPa}$; thus, the measured slope of the obtained S-N curve is higher for HSS based on the current test results. This observation might have large benefits for assessment of Hungarian bridges as presented in [16].

- Test results showed that different types of structural details have different fatigue properties and can have differences between NSS and HSS structures. In some cases, the assumption that fatigue properties of NSS and HSS are identical is applicable. However, it was shown that there are other detail types where this assumption is clearly false. According to the current test results, it can be stated that the widely accepted theory about the fatigue strength of as-welded structural details are not correct for all detail types.

- Based on the strain measurements the cruciform type structural details are extremely fatigue crack sensitive. Their fatigue life is dominated by crack initiation phase. Therefore, in cases of cruciform type details the fatigue strength is higher when HSS material is used instead of NSS.

- Analyzing the measured data of strain gauges, it can be concluded that crack initiation part of the entire fatigue lifetime is dominant for as-welded details as well. Assumption this part is negligible during lifetime calculations is not acceptable and this is the reason why favorable fatigue behavior of HSS details

\section{References}

[1] CEN "EN 1993-1-9 Eurocode 3: Design of steelstructures - Part 1-9: Fatigue", European Comittee for Standardization, Brussels, Belgium, 2005.

[2] Hobbacher, A. "Recommendations for Fatigue Design of Welded Joints and Components", International Institute of Welding, Paris, France, Documentum number: XIII-1965-03/XV-1127-03, 2004.

[3] Maddox, S. J. "Fatigue Design and Assessment of Welded Joints", In: Proceedings of the Ninth International Conference on Fracture, Sydney, Australia, 1997, pp. 2287-2298. can be recognized in some cases. However, the currently applied S-N curves are not affected by this observation, the fracture mechanics based fatigue life calculations cannot be correct without taking account the crack initiation phase for as-welded details as well.

- The results of previous and current research program showed the same conclusion, there is no significant difference between the crack propagation rates of NSS and HSS materials. Fatigue lifetime belonging to this part is more or less the same. Under fatigue load real benefit of HSS materials comes from longer crack initiation phase.

- Results also proved that application of HSS can be beneficial due to the size effect in the case of cruciform type joints as well. Thinner plates have significantly longer fatigue lifetime, as proved by the current experimental research program as well.

Summarizing it can be stated that the fatigue behavior of as-welded HSS structural details is more complex than the previous investigations showed. This paper showed that there are some assumptions that should be revised. To understand the fatigue phenomenon of HSS structures, more experiments are necessary, which are currently under preparation. However, it can be recognized that there are special cases when applying HSS in a fatigue sensitive structure can be a more favorable than using NSS. Application of HSS is better, if crack initiation phase dominates the fatigue behavior, e.g. cruciform type joints. For these detail categories the fatigue lifetime increasing effect of HSS can be considered.

\section{Acknowledgement}

The presented research results are part of the "BridgeBeam" R\&D project No. GINOP-2.1.1-15-2015- 00659. The financial support is gratefully acknowledged. This paper was also supported by the János Bolyai Research Scholarship of the Hungarian Academy of Sciences.

[4] Schijve, J. (ed.) "Fatigue of Structures and Materials", Springer, Dordrecht, Netherlands, 2009. https://doi.org/10.1007/978-1-4020-6808-9

[5] Maddox, S. "Assessing the Significance of Flaws in Welds Subject to Fatigue", presented at The 55th AWS Annual Meeting, Houston, TX, USA, May, 6-10, 1974. [online] Available at: https:// app.aws.org/wj/supplement/WJ_1974_09_s401.pdf [Accessed: 25 February 2020] 
[6] Anami, K., Miki, C. "Fatigue strength of welded joints made of highstrength steels", Progress in Structural Engineering and Materials, 3(1), pp. 86-94. 2001.

https://oi.org/10.1002/pse.52

[7] Pasternak, H., Chwastek, A. "Fatigue Assessment of Non-Load Carrying Fillet Welds", presented at the 7th European Conference on Steel and Composite Structures (EUROSTEEL 2014), Naples, Italy, Sept, 10-12, 2014.

[8] Frank, K. H. "The fatigue strength of fillet welded connections", PhD Dissertation, Lehigh University. 1971. [online] Available at: https://digital.lib.lehigh.edu/fritz/pdf/358_F37.pdf [Accessed: 25 February 2020]

[9] Okawa, T., Nose, T., Shimanuki, H., Suzuki, T. "Fatigue Life Prediction of Welded Structures Based on Crack Growth Analysis" Nippon Steel Technical Report No. 102, 2013. Available at: https://www. nipponsteel.com/102_10_Okawa.pdf [Accessed: 25 February 2020]

[10] Fricke, W. "Evaluation of Hot Spot Stresses in Complex Welded Structures", In: Proceedings of the IIW Fatigue Seminar, Commission XIII, International Institute of Welding, Tokyo, Japan, 2002, pp. 165-176.

[11] Aygül, M., Al-Emrani, M., Urushadze, S. "Modelling and fatigue life assessment of orthotropic bridge deck details using FEM", International Journal of Fatigue, 40, pp. 129-142, 2012.

https://doi.org/10.1016/j.ijfatigue.2011.12.015
[12] Radaj, D., Sonsino, C. M., Fricke, W. "Fatigue Assessment of Welded Joints by Local Approaches", 2nd ed., Woodhead Publishing, Cambridge, UK, 2006. https://oi.org/10.1533/9781845691882

[13] Pijpers, R. J. M., Kolstein, M. H., Romeijn, A., Bijlaard, F. S. K. "Fatigue experiments on very high strength steel base material and transverse butt welds", Advanced Steel Construction, 5(1), pp. 14-32, 2009.

https://doi.org/10.18057/IJASC.2009.5.1.2

[14] Schneider, C. R. A., Maddox, S. J. "Best practice guide on statistical analysis of fatigue data", The Welding Institute, Cambridge, UK, Rep.13604.01/02/1157.02, 2003. [online] Available: https:// www.twi-global.com/pdfs/best-practice-guides/best-practiceguide-on-statistical-analysis-of-fatigue-data.pdf [Accessed: 25 February 2020]

[15] Howell, D. C. "Statistical Methods for Psychology", Wadsworth Cengage Learning, Belmont, CA, USA, 2013.

[16] Platthy, P., Jaramani, R. "Fatigue examination in steel railway bridges using Hungarian traffic types", Periodica Politechnica Civil Engineering, 41(1), pp. 51-57. 1997. [online] Available at: https:// pp.bme.hu/ci/article/view/3741 [Accessed: 25 February 2020] 